\title{
Melodic Features of Cause and Result Clauses in Modern English in the Light of Experiments
}

\author{
Gulyaz Zeynally ${ }^{1}$ \\ ${ }^{1}$ Azerbaijan University of Languages, Baku, Azerbaijan \\ Correspondence: Gulyaz Rza Zeynally, Department of English Grammar, Azerbaijan University of Languages, \\ Baku, Azerbaijan. E-mail: gulyaz.zeynalli@gmail.com
}

Received: September 8, 2016

Accepted: November 1, 2016 Online Published: January 19, 2017

doi:10.5539/ijel.v7n2p167

URL: http://dx.doi.org/10.5539/ijel.v7n2p167

\begin{abstract}
Variability of language units is the main feature of a language system and its activity. Variability has distinctive features providing processes like coding, decoding, maintaining and transforming the information from one generation to the other. One of the characteristic features of modern linguistics is the identification of invariants in every level of a language system. It helps us to say that an invariant is the factor that provides the unity of elements but a variant distinguishes different steps of this unity. Variability of language units is the main means providing the communicative function of the language, or "the possibility of variability of language units is the characteristic feature of the language nature", as G. V. Stepanov says. (Stepanov, 1976, p. 223)

Variability is the characteristic feature of the realization of the units of phonological, morphological and syntactic levels of the language in syntagmatics, in other words the units of these levels are represented in variants in the speech act. The study of variability of the sentence intonation can be a great contribution to the development of the variability problem. Our aim is to investigate melodic contour of adverbial clauses of cause and result, the direction of intonation contour, the interval between syntagms and their register.
\end{abstract}

Keywords: variability, intonation contour, variant, invariant, syntagm, syntagmatic division, melody, tone, semantics, diapason, linguistic and non-linguistic factors, acoustic parameters, oscillogram, intonogram

\section{Introduction}

The theoretical background of the article is based on some considerations, which were underlined in the works of distinguished linguists F. Y. Veysalli \& L.V. Sherba.

To define the composition of units of language levels and their variants, to study the mutual relation between variant and invariant, to determine precise criteria for defining the variability diapason of separate language units, etc. are actual problems in linguistics. The problem of variability has always attracted the researchers' attention and theoretical study of variability of language units is one of the actual problems.

Defining a syntagm as a minimal intonation unit of speech flow, formed in the process of speech, L. V. Sherba characterized it as a unity of meaning and a material expression (Sherba, 1963, p. 87).

Syntagm is not only an acoustic- physiological fact, but also a pure linguistic fact, because the borderline between syntagms is not arbitrary, and syntagm is defined for the close connection between its components. The rising or falling tone within a syntagm makes an intonation pattern, expresses its syntactic structure and meaning. Syntagm gains a concrete meaning only in the process of speech. The meaning of a syntagm depends on the meaning of the whole utterance and its semantic meaning can vary due to the speaker's intention. It should also be added that the main feature of the syntagmatic division of the speech is the indivisibility of the syntagm for its intonation. Both the syntactic structure of the sentences and the syntactic structure of the syntagms should be taken into consideration while choosing language materials for the study of the sentence structure. The position of the syntagmatic stress playing the crucial role in this division must be taken into account too (Yadigar, 1993, p. 174).

Syntagmatic division of the sentence is connected with its logical syntactic structure and the speaker's attitude to the spoken about. The division based on the speaker's attitude to the phrase is changeable and undergoes variability in the same sentence performed by different speakers. 


\section{Literature Review}

Variability being an immanent feature of the system is manifested in an expression and meaning and its main essence is in invariants which always keep their characteristic feature. According to F. Y. Veysalli "variability happens because of two immanent features of the language, like its iconicity and systematic characteristics. The first of them includes variability possibilities in an implicit way, and the second doesn't allow the variant of one language unit to pass to the activity line of the other one and they control the diapason regulating the formation of new invariant from a variant and the combination of two variants in one invariant.

According to G. P. Torsuyev, "constancy and variability are the main features of the language structure. ....the language cannot exit and develop without them. ...variability shows itself in every level of the language and in their units in accordance with the characteristic feature of every level (Torsuyev, 1977, p. 3).

According to Zinder, "A close connection between intonation and the meaning of the sentence makes it one of the main factors of communication... it is not necessary to understand all the words in the sentence to get its meaning. The context makes it possible "to restore" the word, which was not heard, even when restoration does not happen, understanding the meaning of a sentence is not excluded... and intonation plays an important role in this case." (Zinder, 1979, p. 268)

Linguistic and non-linguistic factors such as the length of the phrase, its syntactic structure, its position, the number of different types of stress, intonation -content division, context and situation, the speaker's intention, etc. can affect the realization of intonation variability.

Like other units of the language, intonation contour can undergo variability, i.e. it can be represented in speech, in variants for to their utterance or meaning. The variability of the utterance forms intonation types every intonation contour of which differs in acoustic - articulatory features from one another and can be replaced by a neutral member of the line.

Studying the characteristic features of intonation of composite-complex sentences, D. N. Yunusov writes: “... the intonation structure of these units is always closely connected with grammar. The intonation structure of the composite-complex sentences, as well as their grammatical characteristics are the expressions of common conformity of language functions." (Yunusov, 2008, p. 7)

Intonation provides the adequate perception of the speech in a concrete communicative situation. In this case intonation demonstrates a balanced interrelation of the language and non-language factors in the speech, by representing a fixed expression of communicative semantics of heterogeneous language means.

Pause, the change of melodic contour - the direction of general melodic movement (falling, rising), increase or decrease of intensity, the variability of speed of utterance on syntagm boundary were considered as boundary markers of syntagm. The composite-complex sentence is composed of main syntagms-principal and subordinate classes. In adverbial complexes of cause and result the principal and subordinate clauses are characterized according to their division into stable syntagms.

According to L. R. Zinder "melody serves to express communicative types of a sentence-declarative, interrogative and affirmative more than the other components of intonation." (Veysalli, 2009, p. 274).

It serves not only the division of speech acts, but also connection of its different parts. "...A rising intonation in final position can express question, exclamation, surprise, doubt, hesitation, interest, suggestion, politeness or non-finality. ...A falling tone in speech is either an indicator of an independent meaning and a syntactical unit or a completion of any complex." (Veysalli, 2009, p. 272). According to Veysalli “...the rise-fall of tone makes its melody." As the results gained at the end of the research work depend on the calculation of value of the tone (frequency), this matter requires a special attention." (Yadigar, 1993, p. 177)

\section{Methodology}

Praat computer program was used for an experimental method to get oscillogram and intonogram of adverbial clauses of cause and result. For this purpose some sentences were chosen and recorded by the English language speakers and then inserted into this program to do speech analysis.

\section{Results}

Three types of intonation contour have been registered: with positive, negative intervals and equal intervals.

1). A positive interval between syntagms can be interpreted like this: as a terminal syntagm stands in post-position, it has falling and rise-fall intonation contour, a characteristic feature of complete intonation. The same occurrence takes place in the progredient syntagm as well. The falling level at the end of a progredient 
syntagm proves its having a complete intonation.

In such sentences melody in last syllables of a terminal syntagm is lower than the melody indicators of beginning syllables of a terminal syntagm.

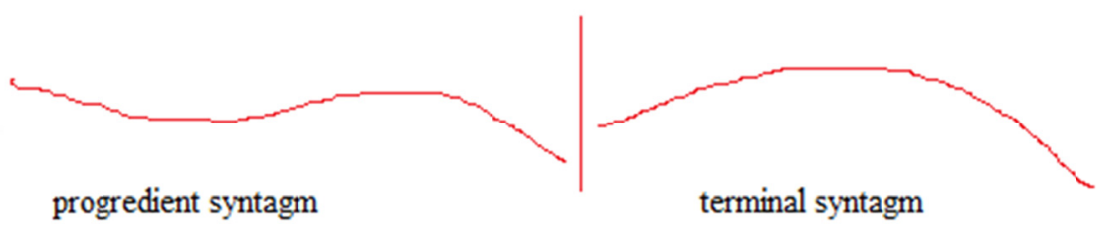

2). Negative interval means the melody contour of the first syntagm has an obvious incompleteness. Fall-rise intonation contour keeps on in the last syllables as well, and, thus the melody peak of the first syntagm prevails over the beginning level of the second syntagm.

A significant difference in negative interval is compensated by the absence of pause between syntagms and syntagmatic division. (keeps its accuracy, exactness)

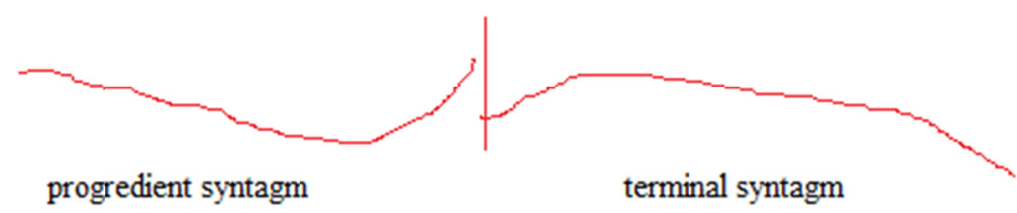

3). In the intonation contour of equal levels either syntagm has the same tonal arrangement.

The second syntagm begins with the tonal level that the first syntagm is over and repeats its rising-falling main tone frequency.

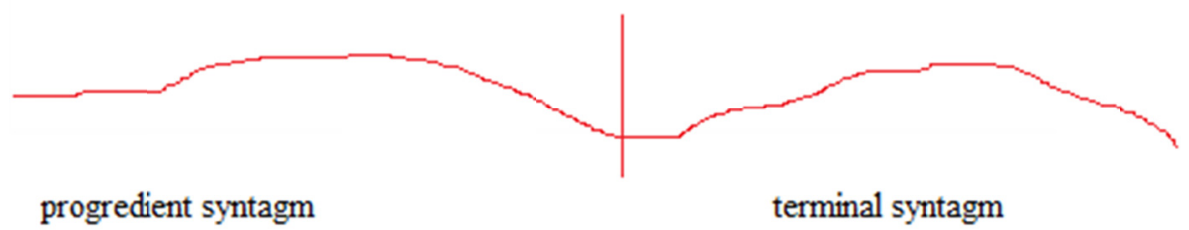

\section{Discussion}

Findings of the current study prove that the structure of melody change is composite, some measures and parameters are used to show the characteristic features of the whole melodic contour and its separate parts.

The most important of them are: the direction of intonation contour, the interval between syntagms, register, the diapason of indicators of acoustic parameters in syntagms, utterance temp and position of melody peak. The changing of rising direction of main tone in the frame of terminal tone or in intonation contour is mainly connected with the purpose of utterance.

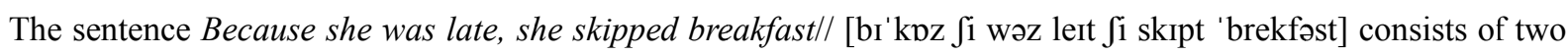
syntagms. The subordinate clause is a progredient syntagm, while the principal clause is a terminal one. However, in the complex this interval is $274-232 \mathrm{hs}$ in the subordinate clause, and 236-208 hs in the principal clause. Maximum value of tone frequency is at the beginning of syntagms: $305 \mathrm{hs}$ and $267 \mathrm{hs}$. In the sentence [bi'kpz Ji wəz leit $\int \mathrm{i}$ skipt 'brekfəst] the indicator according to the components is 269: 240hs. In the analyzed sentences the melody is accompanied by a gradual falling intonation as in declarative sentences. 


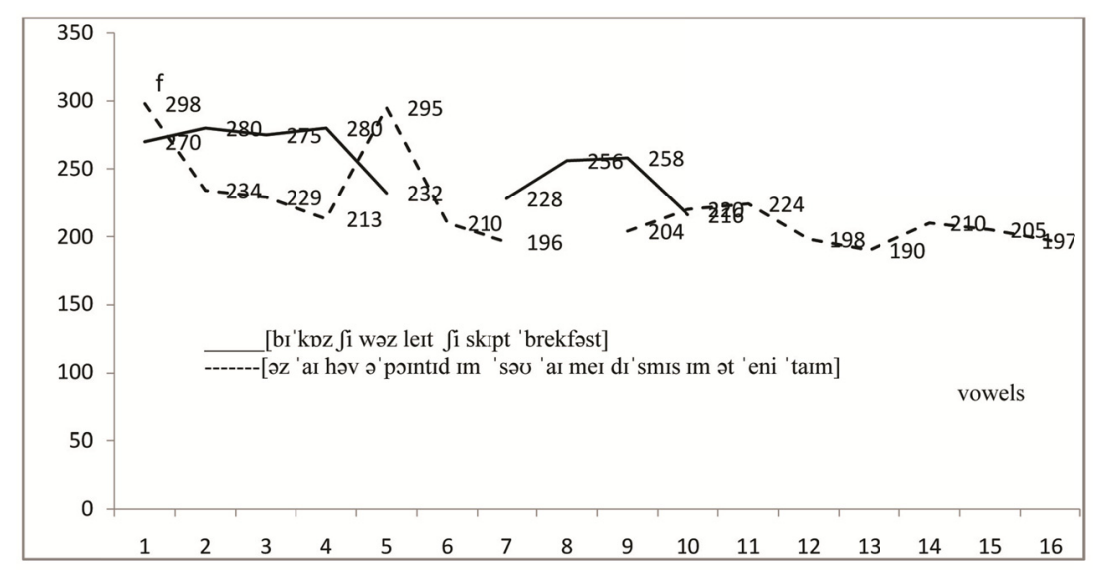

Graph 1. Melodic indicators of the sentences [bi'kpz $\int i$ wəz leit $\int i$ skipt 'brekfəst] and [əz 'aI həv ə' pəIntId Im 'səひ 'ai mei di'smis im ət 'eni 'taim]

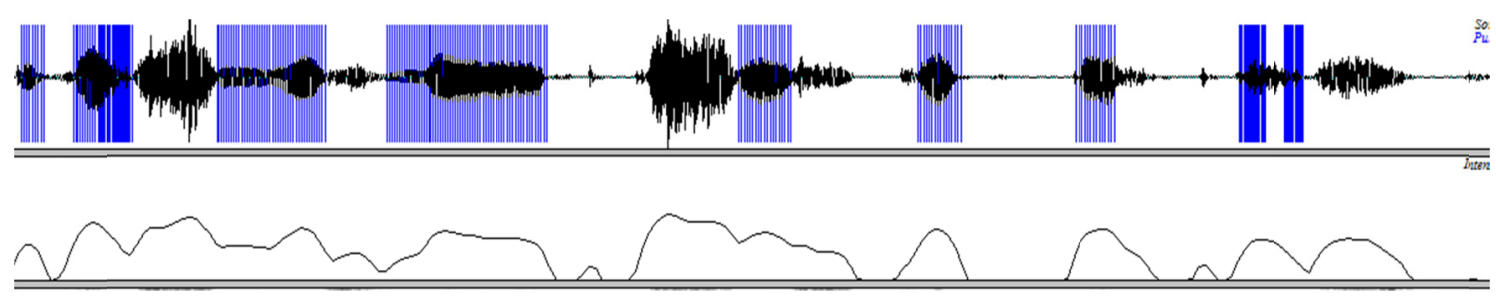

Picture 1. The oscillogram and intonogram of a two-syntagm sentence /Because she was late, she skipped breakfast//

In the sentence /As I have appointed him, so I may dismiss him at any time// [əz 'aI həv ə' porntId Im 'səo 'a meI di'smis Im ət 'eni 'taim] the melody is 298-196hs in the subordinate clause, and 204-210 hs in principal clause (terminal syntagm). (See Graph 1)

In the analysed sentence/Since you're not having anything else, you can have two of everything// [sins jo npt

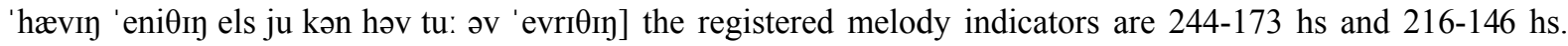
(See Graph 2)

In the complex /Foras much as the thirst is intolerable, the patient may be indulged// [fərəz' $\mathrm{m} \Lambda \mathrm{t} \int \partial_{\mathrm{z}}$ ठə $\theta 3$ :st $\mathrm{s}$

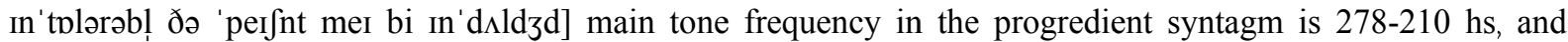
228-211 hs in the terminal syntagm. Though melody has minimum indicators at the end of subordinate clause (progredient syntagm), it is relatively higher than the indicators of the terminal syntagm. (See Graph 2) 


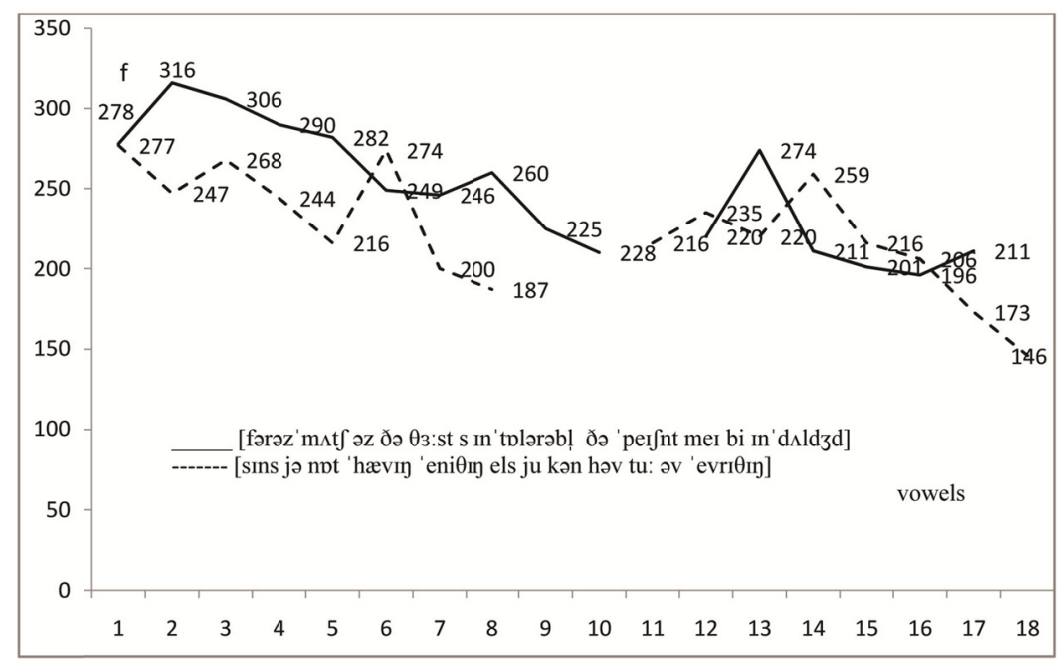

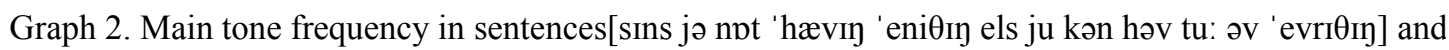

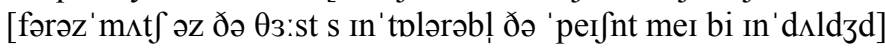

In the complex /And for that wine is dear, we will be furnished with our own// [ənd fə ðət waIn $\mathrm{z}$ diə wi wil bi 'fз:nIft wið 'avər əon] melody in the subordinate clause standing in preposition is 249-244 hs, but 268-192 hs in principal clause. (See Graph 2)

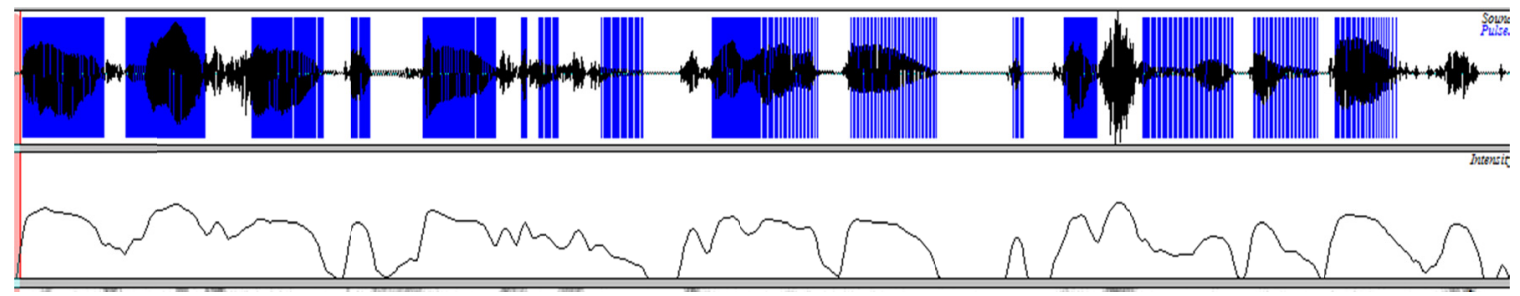

Picture 2. The oscillogram and intonogram of a two-syntagm complex sentence [fərəz' $\mathrm{m} \Lambda \mathrm{t} \int \partial \mathrm{z}$ ðə $\theta 3$ :st s

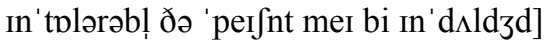

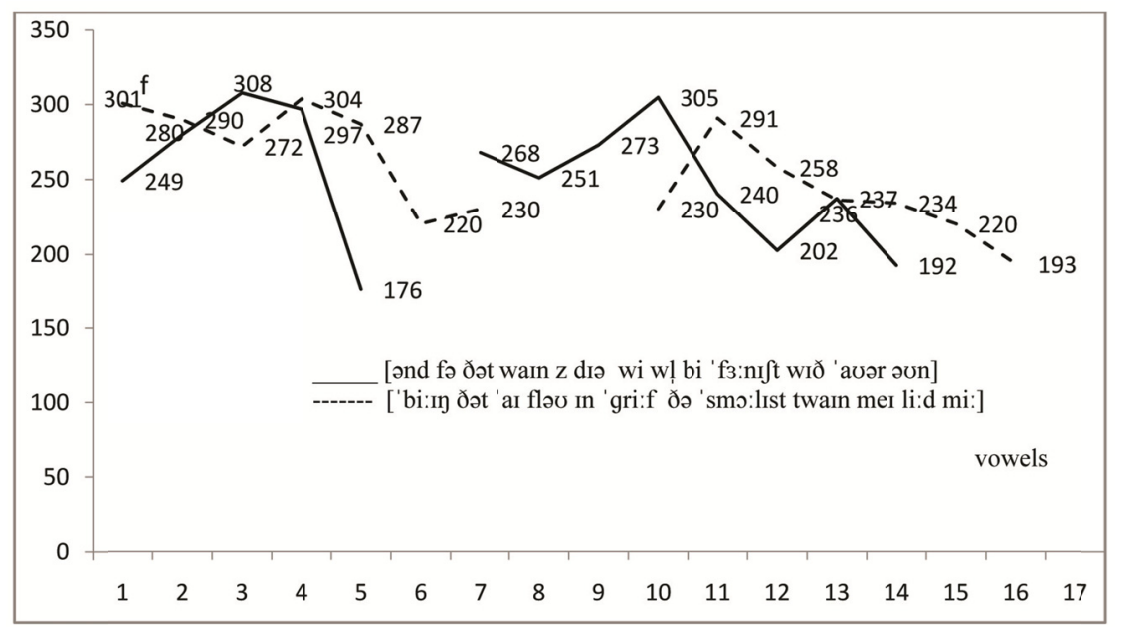

Graph 3. Main tone frequency in sentences [ənd fə ðət wain z dıə wi wil bi 'fз:nıft wıð 'aひər əun] and ['bi: In ðət 'ar fləひ In 'gri:f ðə 'smə:lıst twain mer li:d mi:] 
In the sentence/Being that I flow in grief, the smallest twine may lead me// ['bi:Inðət 'arfləoin 'gri:fðə 'smo:listtwanmerli:d mi:] the indicators for aprogredient syntagm is 301-230 hs and for a terminal syntagm 230-193 hs.

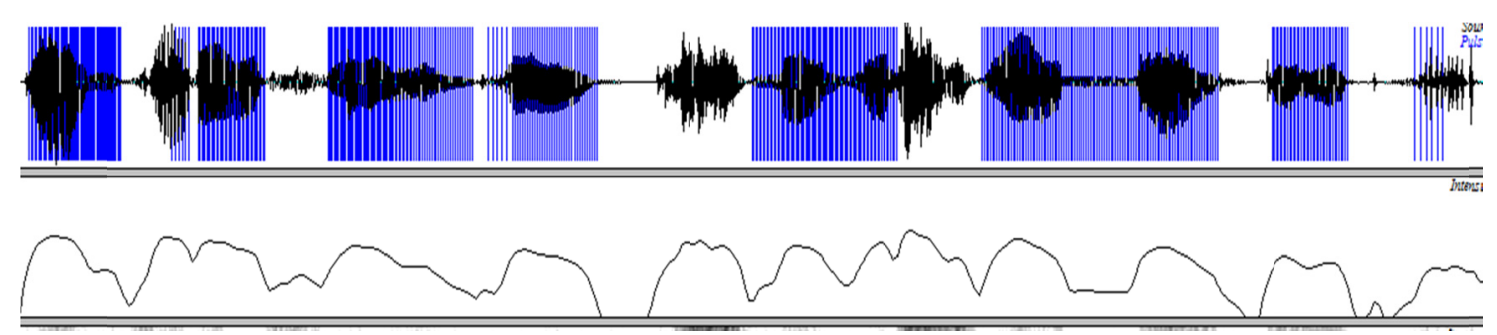

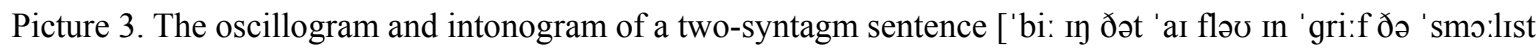
twain mer li:d mi:]

An analogical situation is observed in post- position subordinate clauses of a composite complex sentence. For example, in the sentence /I question my agenow because I feel twice it// ['aI 'kwestfon mar eIdz nav bI'knz 'aI fi:l twars It] melody in the progredient syntagm (principal clause) is 290-208 hs and 270-172 hs in the terminal syntagm. Maximum tone frequencies are registered at the beginning of syntagms: $290 \mathrm{hs,} 270 \mathrm{hs}$. (See Graph 4)

In the sentence/It all happened because Barbara got lost// [It $\mathrm{s}: 1$ 'hæpənd bI'kpz 'ba:brə 'gpt lost] melody begins with a middle register in the principal clause. Maximum tone frequency was registered in the second syllable of a progedient syntagm $-307 \mathrm{hs}$. Maximum tone frequency in the terminal syntagm was registered in the second syllable. The interval difference of main tone frequency within syntagms is 37 hs (See Graph 4)

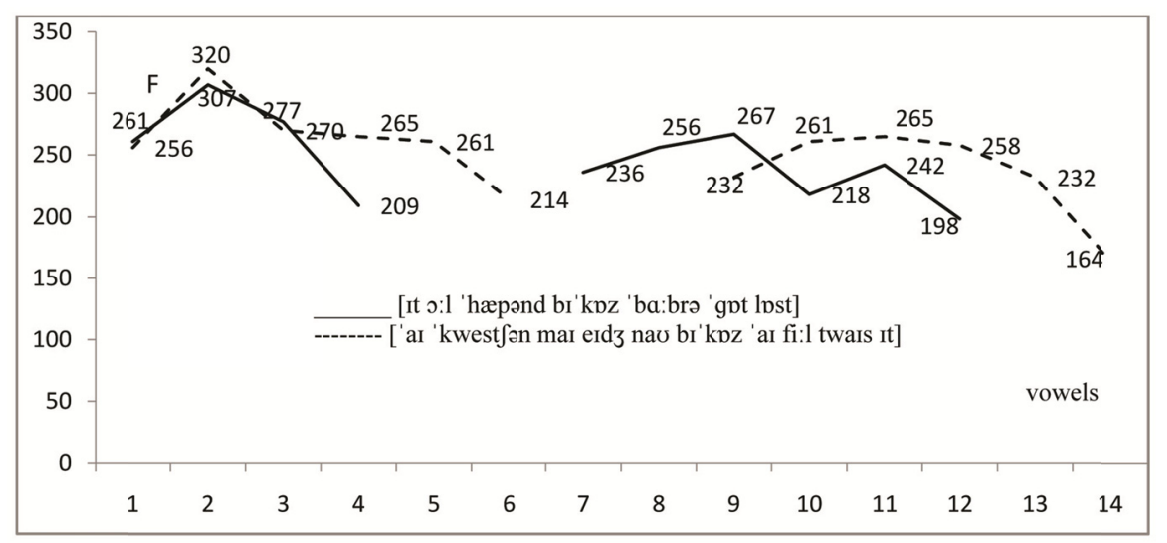

Graph 4. Main tone frequency of the sentences ['ar 'kwest əən mar eIdz nav bi 'kpz 'ar fi:l twais it] and [It o:l 'hæpənd bi' kpz 'ba:brə 'gnt lost]

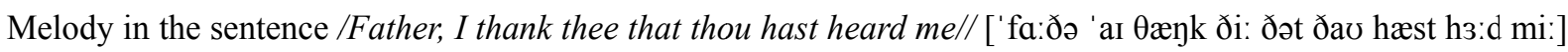
begins with a middle register then it gets its peak in the second and third syllables and has a minimum frequency at the end of the syntagms. Main tone frequency between syntagms is distributed as $268-241 \mathrm{hs}$. The minimum tone frequency was observed in the last syllable of a terminal syntagm in the complex whole, which is $183 \mathrm{hs}$. (See Graph 5) 


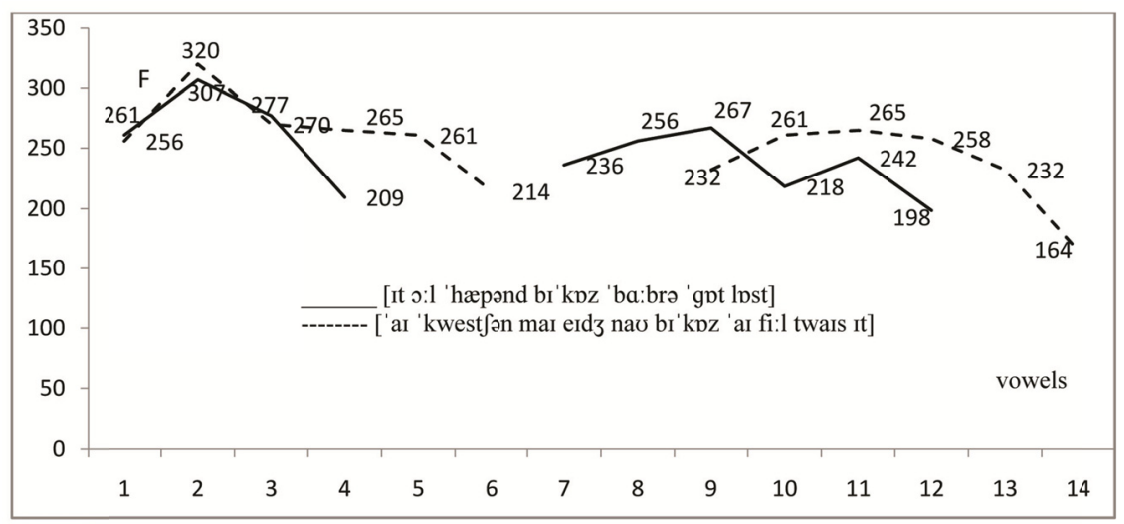

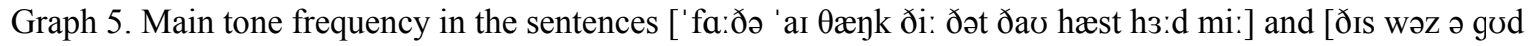
dı'sızn , I'næsmıt $\int$ əz It w3:kt fə ju]

The main tone frequency in the sentence /This was a good decision inasmuch as it worked for you// [ðıs wəz ə god dı' sızn , I'næsm $\Lambda \mathrm{t} \int \partial \mathrm{z}$ It w3:kt fə ju] is distributed as 353-216 hs and 219-206 hs according to syntagms.

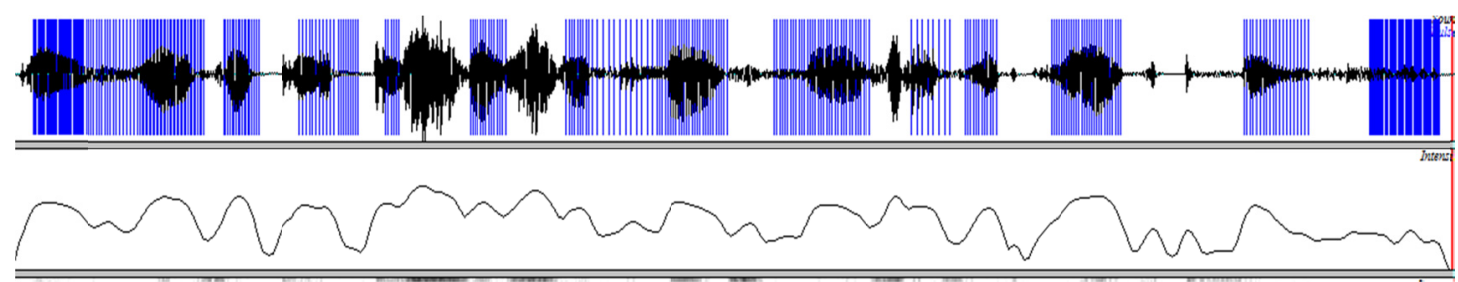

Picture 4. The oscillogram and intonogram of a two-syntagm sentence [ðIs wəz ə god dı'sızn, , I'næsm $₫$ t əz It w3:kt fə ju]

In the analyzed composite complex sentences result clauses are used in post positions. In the sentences/We arrived early, so that we got good seats// [we ə' rarvd '3:li /'səu ðət wi 'got god si:ts], /She sat behind me so that I

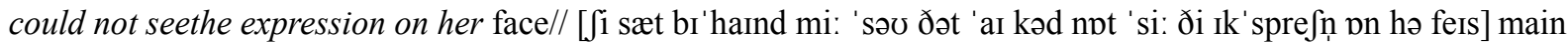
tone frequency in terminal syntagms is $247-197 \mathrm{hs}, 260-216 \mathrm{hs}$ and $245-190 \mathrm{hs}, 247-164 \mathrm{hs}$ in terminal syntagms. An avarage value of main tone frequency of syntagms is $238 \mathrm{hs}, 247 \mathrm{hs}, 252 \mathrm{hs}$ in progredient syntagms and in terminal syntagms that is $216 \mathrm{hs}, 228 \mathrm{hs}, 232 \mathrm{hs}$. (See Graph 6)

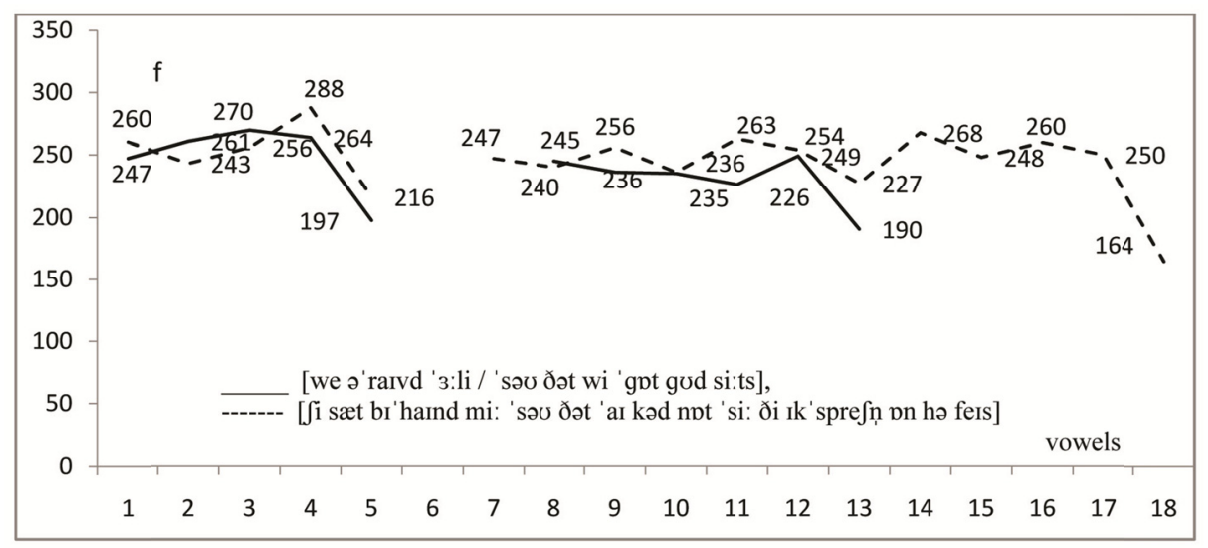

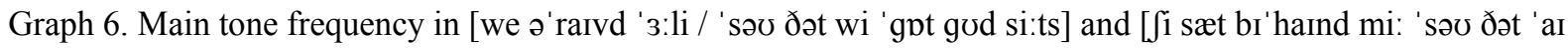

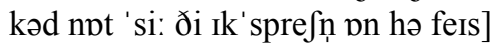




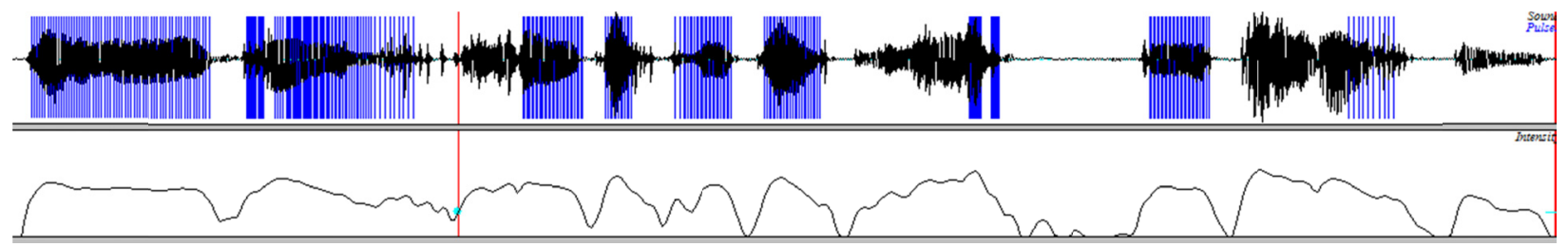

Picture 5. The oscillogram and intonogram of a two-syntagm sentence [we ə' rarvd '3:li /'səひ ðət wi 'gpt god si:ts]

The complex sentence Her joy was so great that she stood fascinated// [hə dзəI wəz 'səu 'greIt ðət $\int \mathrm{i}$ stud 'fæsinertid] was pronounced as a two-syntagm sentence by both of the speakers. The main tone frequency in the progredient syntagm is 261-266 hs and $271-191 \mathrm{hs}$ in a terminal syntagm. Average tone frequencies in progredient syntagms are $263 \mathrm{hs}$ and $232 \mathrm{hs}$. Melody relatively rises in progedient syntagms which informs about incompleteness of thought. (See Graph 7)

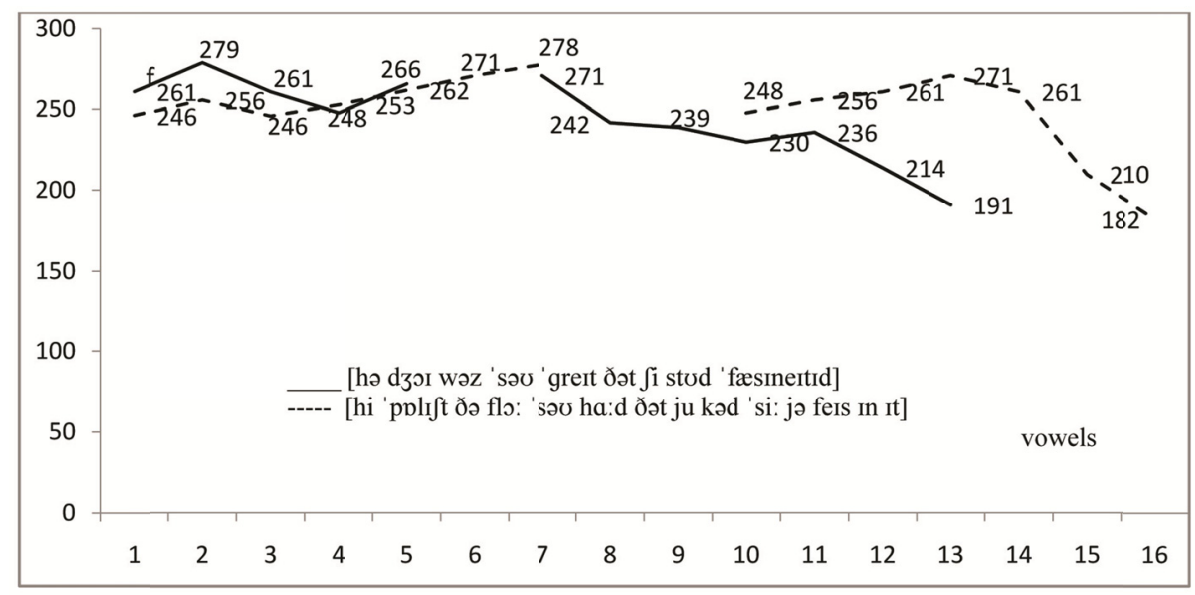

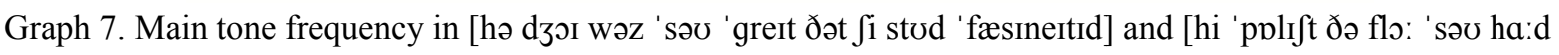
ðət ju kəd 'si: jə feIs In It]

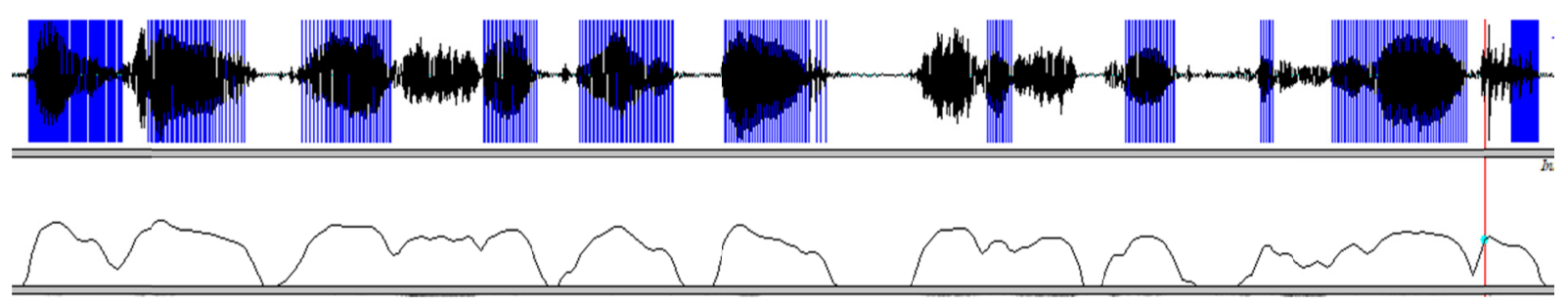

Picture 6. The oscillogram and intonogram of a two-syntagm sentence [hə dзər wəz 'səひ 'greit ðət $\int i$ stud 'fæsinertid]

In the sentences/He polished the floor so hard that you could see your face in it// [hi 'pplift ðə flo: 'səo ha:d dət ju kəd 'si: jə feIs In It], /The atmosphere was so bad that I was happy to leave them// [ði 'ætməsfiə wəz ' səu bæd ðət 'aI wəz 'hæpi tə li:v ðəm] main tone frequencies in post position subordinate clauses are 248-182 hs, 258-251hs. These indicators for a progredient syntagm i.e., for a principal clause are 246-276 hs and 246-196 hs.

The rise of main tone frequency in the last syllable of the progredient syntagm in the sentence [hi 'pvlift $\partial ə$ flo: 'səひ ha:d / ðət ju kəd 'si: jə feIs In It]| can be because of the acoustic quality of the vowel |a: |

Average tone frequency in progredient syntagms in complex wholes is $258-270 \mathrm{hs}$, and in terminal syntagms 236-246 hs, the difference in interval between syntagms is $27-12-24 \mathrm{hs}$.

A strong weakening of main tone frequency in the last stressed vowel is a characteristic feature of intonational completeness. Weakening of the main tone frequency undergoes a great variation not only in the stressed vowel, 
but also within the whole sentence, and the last stressed vowel gets a lower position in consequence to average tone frequency.

F. Veysalli analyses tone movement in sentences with two or more syntagms like this:

The level of main tone frequency of the last syntagm in the sentences with more than one syntagm is the same with that in one syntagm sentences (Yadigar, 1993, p. 190).

The pitch movement must be compared at the end of syntagms to define conformity of melodic structure of sentences with two or more syntagms. Maximum weakening of main tone frequency is a characteristic feature in last syllable of a terminal syntagm in various syntactic structures (Yadigar, 1993, p. 225).

F. Veysalli notes that maximum fall in melody is not connected with the syntactic structure: in melodic description the peak can be at the beginning or in the middle, but common movement of main tone keeps its falling direction (Yadigar, 1993, p. 191).

Though the sequence of the components of a complex syntactic whole (principal and subordinate clauses) is connected with the situation every time, it is also free to some extent, i.e., it serves variability of replacement of principal and subordinate clauses.

\section{Conclusion}

Following results have been obtained from acoustic analyses of intonation properties of complex sentences with cause and result clauses in modern English: The inphrase and outphrase function of the intonation form theoretical basis of the experiment. The outphrase function of the intonation serves to the communicative composition of the phrase and inphrase function serves to its organization and syntagmatical division.

The acoustic indicators of the endings of principal and subordinate clauses (progredient and terminal syntagms) in two syntagm sentences have been compared in order to determine intonation contour of a complex whole. The analysis of acoustic parameter shows that there is a maximum fall of melodiousness, weakening of intensity and delay of pronunciation speed at the end of terminal intonation contour. The acoustic parameters show that relevant features of terminal intonation contour is located at the end of terminal syntagm. The fall of intonation contour within the analyzed complexes show the border between syntagms. While the weakening of the tone is specific to the end of progredient and terminal syntagms it is constant and minimal indicator at the end of the terminal syntagm. (regardless of the sentence being principal or subordinate clause). The melodiousness is variable at the end of progredient syntagm, i.e., it is either equal to the total relative average value of the syntagm or below the average relative value. Acoustic analysis of the components of a complex whole- principal and subordinate clauses- shows that the intonation contour of the components of a syntactic complex is not dependent on the order of principal and subordinate clauses.

\section{References}

Sherba, L. V. (1963). Photenitcs of the French language (p. 308). Moscow: Visshaya Shkola.

Stepanov, G. V. (1976). About the peculiarity of language variability. Language theory. Anglistics, Celtology (p. 280). Moscow: "Nauka".

Torsuyev, G. P. (1977). Constantivity and variability in phonetic system (p. 125). Moscow: "Nauka".

Veysalli, F. Y. (2009). Selected works, I, p. 640. Baku: Mutarjim.

Yadigar (Veysalli), F. Y. (1993). Problems of phonetics and phonology (p. 192). Baku: Maariph.

Yunusov, D. N. (2008). Constantivity and variability in syntactic complexes (p. 164). Baku: E. L. Printhouse and Polygraphy MMC.

Zinder, L. R. (1979). General phonetics (Textbook. II edition, p. 312). Moscow: Visshaya shkola.

\section{Copyrights}

Copyright for this article is retained by the author(s), with first publication rights granted to the journal.

This is an open-access article distributed under the terms and conditions of the Creative Commons Attribution license (http://creativecommons.org/licenses/by/4.0/). 